\title{
Inducing Efficiency in Oligopolistic Markets with Increasing Returns to Scale*
}

\author{
Abhijit Sengupta ${ }^{\dagger}$ and Yair Tauman ${ }^{\ddagger}$
}

February 6, 2004

\begin{abstract}
We consider a Cournot Oligopoly market of firms possessing increasing returns to scale technologies. It is shown that an external regulating agency can increase total social welfare without running a deficit. It offers to subsidize one firm an amount which depends on the output level of that firm and the market price. The firms bid for this contract and the regulator collects the highest bid and subsidizes the highest bidding firm. It is shown that there exists a subsidy schedule such that (i) The regulator breaks even (namely the winning bid equals the total subsidy) (ii) The winning firm obtains zero net profit and charges a price equal to its average cost (iii) Every other firm willingly exit the market and (iv) Market price decreases, consumers are better off and total welfare improves.
\end{abstract}

Keywords: Regulation, Oligopoly, Increasing Returns.

JEL Classification: D43, H21, L11, L13, L51.

*The authors wish to thank Ehud Kalai, Roger Guesnerie, Yossi Speigel and Sandro Brusco for useful discussions and suggestions.

${ }^{\dagger}$ Department of Economics, State University of New York at Stony Brook, Stony Brook, NY 11794-4384. Email: abhijit.sengupta@sunysb.edu

${ }^{\ddagger}$ Department of Economics, State University of New York at Stony Brook, Stony Brook, NY 11794-4384 and Faculty of Management, Tel Aviv University, Ramat-Aviv, Tel-Aviv 69978, Israel. Email: tauman@post.tau.ac.il 


\section{Introduction}

The central motivation of this paper is to come up with a mechanism which promotes efficiency in an oligopolistic industry which is characterized by increasing returns to scale but operating inefficiently. We show that there exists a mechanism which provides incentives to existing firms in an industry to implement a strictly welfare improving outcome. Specifically this mechanism makes a command structure redundant, where production and pricing decisions of firms are controlled by a regulatory authority.

We arrive at incentive mechanisms by which a benevolent regulator is able to implement, without running a deficit, a welfare improving outcome by making every Cournot oligopolistic firm but one voluntarily exit the market. Additionally, the existing monopolist willingly produces and prices more efficiently and the society is better off.

To be more specific, the regulator offers a contract to exclusively subsidize one firm - the one who is willing to pay him the highest upfront fee for that contract. The subsidy offered by the regulator is of the form of a non-linear scheme which depends on the output of the winning firm and market price. It is shown winning firm sets a price equal to average cost and obtains zero net profit. All other firms exit the industry and the regulator breaks even. The total welfare of the society is improved.

In a classic paper, Demsetz (1968) points out that regulation of a monopolistic firm might be carried out in the entry stage itself. In an industry which is a natural monopoly, suppose the regulator wants to grant a license which gives the right to produce to a single firm. Each firm quotes a bid for the price at which it will sell if granted the license. The firm with the lowest bid would ultimately be awarded the contract to be the monopoly producer in the market. With a large number of firms "competing for the field", the level of competitiveness among potential entrants would ensure that the price charged by the winning monopolist would be close to per-unit cost of production. Demsetz contends that the winner is committed to charge no more than what it bids as it enters a binding legal contract with the regulator. 
Baron and Myerson (1982) and Berg and Tschirhart (1988) deal with ways to control a natural monopoly under asymmetric information, where the firm has more information about its technology than the regulator. Sappington and Sibley (1988) provide a mechanism where a regulator without any cost information about the firm can implement marginal cost pricing and zero rents over multiple periods. In the same vein, Vogelsang and Finsinger (1979) describe an incentive mechanism which induces the management of a multi-product monopoly to adjust the price structure step-by-step in the direction of the optimum. Guesnerie and Laffont (1978) examine the likelihood of the government ensuring a first best outcome in a general equilibrium framework where one of the firms is a monopolist in a particular commodity. They show that when non-convexities are present in the profit function of the monopolist, there exists optimal taxation schemes which ensure optimal pricing by the monopolist. The most comprehensive treatment of a large number of issues related to regulation of a natural monopoly is by Laffont and Tirole (1993).

There have been a few papers dealing with industry structure per se. Auriol and Laffont (1992) discuss costs and benefits of a duopoly structure when marginal costs are private information and fixed costs are common knowledge. A duopoly is preferred by the government if the market structure is to be chosen before marginal costs have been revealed to the firms themselves, whereas a monopoly is socially better if the government needs to fix the market structure after the firms come to know their private marginal costs.

Grimm et al. (2003) examine under incomplete information, the design of mechanisms to implement the optimal market structure assuming that a regulator is unable to control firm behavior once firms have entered the market.

The paper closest in spirit to this one is by Liao and Tauman (2002). It considers an $N$ firm industry with constant marginal costs. It is shown that a certain linear per unit subsidy schedule can induce the socially best outcome while the regulator breaks even in the process. The result is quite straightforward. The regulator offers a linear subsidy to just one firm. If the per unit subsidy is chosen to be the ratio between marginal cost and the price elasticity 
of demand (at marginal cost), then the subsidized firm will produce the efficient outcome. Firms therefore would bid up to the subsidy cost for the right to be subsidized and the regulator will not run any deficit. The current paper generalizes this to the case of a Cournot industry with increasing returns to scale technology.

In many industries, direct regulation might be a necessity given the cost structure, but may not be possible because of political restrictions on government intervention. With the current emphasis on deregulation, it might not even be a desirable course of action. In such a climate, it is up to the regulator to design proper incentive schemes which would make the industry regulate itself. Such a scheme would have to take into consideration not only the motives of the firms themselves, but also the resulting impact on consumers as well as the regulator's own budget.

This paper focusses on the case of complete information. The cost functions and the demand functions are all commonly known by the firms in the market as well as by the regulator. In Section 2 we set up the basic model with symmetric firms and state our main result. In Section 3, we generalize our model to incorporate asymmetry in the firms' technologies.

\section{The Model}

We first examine the situation when there are $N \geq 2$ identical firms producing a single commodity in the market. Market inverse demand is $P(Q)$ each firm's production cost is given by $C\left(q_{i}\right)$. We consider the case where the technology exhibits increasing returns to scale. The firms are engaged in Cournot competition. The demand and cost functions are common knowledge to all agents.

We postulate the following assumptions.

Assumption $1 P(Q)$ is twice differentiable, strictly decreasing and concave, i.e. $P^{\prime}<0$ and $P^{\prime \prime} \leq 0$ for all $Q>0$.

Assumption $2 C(q)$ is twice differentiable for all $q>0 . C^{\prime}(q)>0$ and 
$C^{\prime \prime}(q)<0$ for all $q>0 . \quad C(0)=0$ but $\lim _{q \rightarrow 0} C(q) \geq 0 .{ }^{1}$ Namely, $C(\cdot)$ may include a fixed cost component.

The requirement that $P^{\prime \prime}<0$ is not standard in the literature. However, it guarantees the concavity of the profit functions (see Lemma 1, below) and hence the existence of the Cournot equilibrium. Alternatively, we could drop the concavity assumption of demand and require instead that

$$
2 P^{\prime}(Q)+Q P^{\prime \prime}(Q)-C^{\prime \prime}(q)<0
$$

for all $Q>0$ and all $0<q \leq Q$.

Assumption $3 P(q)-C^{\prime}(q)$ is strictly decreasing for all $q>0$ and there exists $\bar{q}>0$, such that $P(\bar{q})=C^{\prime}(\bar{q})$.

For every $q>0$, let $A C(q)=\frac{C(q)}{q}$. By Assumption 2, $A C^{\prime}(q)<0$ and consequently $A C(q)>C^{\prime}(q)$ for all $q>0 .^{2}$ Assumptions 3 implies that $P(\cdot)$ and $C^{\prime}(\cdot)$ intersect exactly once. Let,

$$
\pi_{i}\left(q_{1}, \ldots, q_{N}\right)=q_{i} P(Q)-C\left(q_{i}\right)
$$

be the profit function of firm $i$, where $Q=\sum_{j=1}^{N} q_{j}$. Then,

$$
\frac{\partial \pi_{i}}{\partial q_{i}}=P(Q)+q_{i} P^{\prime}(Q)-C^{\prime}\left(q_{i}\right)
$$

and

$$
\frac{\partial^{2} \pi_{i}}{\partial q_{i}^{2}}=2 P^{\prime}(Q)+q_{i} P^{\prime \prime}(Q)-C^{\prime \prime}\left(q_{i}\right)
$$

Lemma $1 \frac{\partial^{2} \pi_{i}}{\partial q_{i}^{2}}<0$.

Proof: $\frac{\partial^{2} \pi_{i}}{\partial q_{i}^{2}}=P^{\prime}(Q)+q_{i} P^{\prime \prime}(Q)+P^{\prime}(Q)-C^{\prime \prime}\left(q_{i}\right)$.

\footnotetext{
${ }^{1}$ In particular, we assume that this limit exists.

${ }^{2}$ Clearly, $A C(q)$ is decreasing in $q$ if $\frac{C(q)-C(0)}{q}$ is decreasing. Let $q_{2}>q_{1}$. Then $\frac{C\left(q_{2}\right)-C(0)}{q_{2}}<\frac{C\left(q_{1}\right)-C(0)}{q_{1}}$ if and only if, $\frac{C\left(q_{2}\right)-C\left(q_{1}\right)}{q_{2}-q_{1}}<\frac{C\left(q_{1}\right)-C(0)}{q_{1}}$. But $\frac{C\left(q_{2}\right)-C\left(q_{1}\right)}{q_{2}-q_{1}}=$ $C^{\prime}\left(\xi_{2}\right)$ and $\frac{C\left(q_{1}\right)-C(0)}{q_{1}}=C^{\prime}\left(\xi_{1}\right)$ where $q_{1}<\xi_{2}<q_{2}$ and $0<\xi_{1}<q_{1}$. Since $C^{\prime \prime}(\cdot)<0$, $C^{\prime}\left(\xi_{2}\right)<C^{\prime}\left(\xi_{1}\right)$ and hence $A C\left(q_{2}\right)<A C\left(q_{1}\right)$.
} 
By Assumption 1, $P^{\prime}(Q)+q_{i} P^{\prime \prime}(Q)<0$ and $P^{\prime}(Q) \leq P^{\prime}\left(q_{i}\right)$. Consequently,

$$
\frac{\partial^{2} \pi_{i}}{\partial q_{i}^{2}}<P^{\prime}\left(q_{i}\right)-C^{\prime \prime}\left(q_{i}\right)<0
$$

since $P\left(q_{i}\right)-C^{\prime}\left(q_{i}\right)$ is decreasing (Assumption 3).

Lemma 1 implies the existence of a Cournot equilibrium.

In order to simplify the analysis we focus on a duopoly. The analysis of the general case is a straightforward extension of the duopoly case. Suppose that the total Cournot duopoly output levels of the firms are $Q_{1}^{d}$ and $Q_{2}^{d}$, and let $Q_{1}^{d}+Q_{2}^{d}=Q^{d}, Q_{i}^{d}>0$ for $i=1,2$.

Lemma 2 There exists $q>0$ such that $P(q)=A C(q)$.

Proof: $\quad \pi_{i}\left(Q_{1}^{d}, Q_{2}^{d}\right)=Q_{i}^{d} P\left(Q^{d}\right)-C\left(Q_{i}^{d}\right) \geq 0$. Hence, $P\left(Q^{d}\right) \geq A C\left(Q_{i}^{d}\right) \geq$ $A C\left(Q^{d}\right)$. On the other hand, for each $q>\bar{q}, P(q)<C^{\prime}(q)<A C(q)$ (see Assumption 3). Since $P(q)$ and $A C(q)$ are continuous for $q>0$, by the Mean Value Theorem there exists $q$ such that $P(q)=A C(q)$.

Let,

$$
A=\{q \mid P(q)=A C(q)\} .
$$

Lemma 3 The set $A$ is nonempty and compact.

Proof: See Appendix.

Let,

$$
\widetilde{Q}=\operatorname{Max}_{q \in A} q .
$$

Lemma $4 \widetilde{Q}<\bar{q}$.

Proof: Suppose to the contrary that $\widetilde{Q} \geq \bar{q}$. Then by Assumption $3, P(\widetilde{Q}) \leq$ $C^{\prime}(\widetilde{Q})<A C(\widetilde{Q})$, a contradiction.

Consider a regulator which desires to increase the total welfare of the society. It could be the government or a government run regulatory authority. It is assumed that the regulator has full information about market demand and cost structures of the firms. The interaction between the regulator and the firms is described as follows. 
In the first stage, the regulator announces a subsidy schedule $f(q, Q)$ to be awarded exclusively to one firm. This firm producing $q$ would be awarded a lump-sum amount of $f(q, Q)$. In the second stage, the firms announce simultaneously (or through sealed tenders) their own willingness to pay (bids) for this contract. The firm with the highest willingness to pay is awarded the exclusive contract. In case of a tie, the regulator awards the subsidy randomly to any one firm. The winning firm pays its bid to the regulator. In the last stage, the firms compete a lá Cournot, that is in quantities.

Consider the following subsidy schedule,

$$
f(q, Q)=-q P(Q)+\int_{0}^{q} P(x) d x-\widetilde{t} \cdot q+\delta
$$

where $\widetilde{t}=P(\widetilde{Q})-C^{\prime}(\widetilde{Q}), Q$ is the total industry output and $\delta>0$. The payoff function of the subsidized firm $i$ is,

$$
\pi_{i}^{S}\left(q_{i}, q_{j}\right)=q_{i} P(Q)-C\left(q_{i}\right)+f\left(q_{i}, Q\right)+\delta-\alpha_{i}
$$

where $\alpha_{i}$ is the bid of $i$ and $Q=\sum_{k=1}^{2} q_{k}$. By (4),

$$
\pi_{i}^{S}\left(q_{i}, q_{j}\right) \equiv \pi_{i}^{S}\left(q_{i}\right)=\int_{0}^{q_{i}} P(x) d x-C\left(q_{i}\right)-\widetilde{t} \cdot q_{i}+\delta-\alpha_{i}
$$

and as we see, $\pi_{i}^{S}$ depends only on the quantity produced by the subsidized firm.

The payoff function of the other firm $j, j \neq i$, is

$$
\pi_{j}\left(q_{i}, q_{j}\right)=q_{j} P(Q)-C\left(q_{j}\right)
$$

and the payoff of the regulator is $\alpha_{i}-f_{i}\left(q_{i}, Q\right)$.

The above describes a game $\mathrm{G}$ between the regulator and the firms of the industry.

The parameter $\delta>0$ is chosen to satisfy the inequality

$$
\pi_{k}^{S}(\widetilde{Q})>\pi_{k}\left(Q_{1}^{d}, Q_{2}^{d}\right) \quad k=i, j .
$$

This eliminates an equilibrium where both $i$ and $j$ do not bid for the contract.

We are ready to state and prove our first main result. 
Theorem 1 The game G has an unique subgame perfect equilibrium. The subsidized firm produces the output level $\widetilde{Q}$ and earns a net profit of zero. The other firms exit the market and the regulator breaks even. Finally, the total welfare of the society increases as compared with the no subsidy case.

By (5), for the subsidized firm $i$,

$$
\frac{\partial \pi_{i}^{S}}{\partial q_{i}}=P\left(q_{i}\right)-C^{\prime}\left(q_{i}\right)-\widetilde{t}=P\left(q_{i}\right)-C^{\prime}\left(q_{i}\right)-\left[P(\widetilde{Q})-C^{\prime}(\widetilde{Q})\right]
$$

By Assumption 3, $P(q)-C^{\prime}(q)$ is strictly decreasing. Thus $\frac{\partial \pi_{i}^{S}}{\partial q_{i}}=0$, iff $q_{i}=\widetilde{Q}$. Namely, independent of the output level $q_{j}$ of $j$, firm $i$ is best off producing $\widetilde{Q}$ units, and $\pi_{i}^{S}(\widetilde{Q})=f(\widetilde{Q})-\alpha_{i}$.

We now prove that the other firm $j$ is best off exiting the market given that $i$ produces $\widetilde{Q}$. Firm $j$ will stay in the market only if $\pi_{j}\left(q_{j}, \widetilde{Q}\right) \geq 0$, that is if, $P\left(\widetilde{Q}+q_{j}\right) \geq A C\left(q_{j}\right)$. Since $A C(\cdot)$ is decreasing $A C\left(q_{j}\right)>A C\left(\widetilde{Q}+q_{j}\right)$. Consequently, $j$ may stay in the market only if $P\left(\widetilde{Q}+q_{j}\right)>A C\left(\widetilde{Q}+q_{j}\right)$. Suppose that the last inequality holds and $q_{j}>0$. By Assumption $3, P(q)<C^{\prime}(q)<$ $A C(q)$ for all $q>\bar{q}$. Hence by continuity of $P(q)$ and $A C(q)$ there exists $q$ such that $\widetilde{Q}<q<\bar{q}$ and $P(q)=A C(q)$, a contradiction to the definition of $\widetilde{Q}$. Consequently, $q_{j}=0$ must hold and $j$ exits the market. We can now write the subsidy schedule as $f(q)$ instead of $f(q, Q)$, since $Q=q$.

Lemma $5 f(\widetilde{Q})>0$.

Proof: See Appendix B.

Thus in order to win the subsidy, each firm would be willing to pay its entire gross profit, that is $\alpha_{i}=f(\widetilde{Q})$. Hence, the subsidized firm makes zero net profit in equilibrium and the regulator breaks even. As we have already see, the subsidized firm $i$ produces $\widetilde{Q}$ irrespective of what $j$ produces. $j$ in turn has the unique best response of $q_{j}=0$. Hence this equilibrium is unique.

Note that the lowest price the regulator can induce without running a deficit is $P(\widetilde{Q})=A C(\widetilde{Q})$. The reason is that for any $q>\widetilde{Q}, P(q)<A C(q)$, which means that the gross profit of the subsidized firm is less than $f(q)$. Hence, the regulator will not be able to recover the subsidy. 
We next show that the subsidy schedule of the regulator improves the total welfare of society. The total welfare under the Cournot duopoly is,

$$
T W_{1}=\pi_{i}^{d}\left(Q_{i}^{d}, Q_{j}^{d}\right)+\pi_{j}^{d}\left(Q_{i}^{d}, Q_{j}^{d}\right)+C S\left(Q^{d}\right)
$$

where $C S\left(Q^{d}\right)$ is the consumer surplus. Hence,

$$
\begin{aligned}
T W_{1} & =\pi_{i}^{d}\left(Q_{i}^{d}, Q_{j}^{d}\right)+\pi_{j}^{d}\left(Q_{i}^{d}, Q_{j}^{d}\right)+\int_{0}^{Q^{d}} P(x) d x-Q^{d} P\left(Q^{d}\right) \\
& =\int_{0}^{Q^{d}} P(x) d x-C\left(Q_{i}^{d}\right)-C\left(Q_{j}^{d}\right)
\end{aligned}
$$

On the other hand, the total welfare with the subsidy schedule $f(q)$ is,

$$
T W_{2}=C S(\widetilde{Q})=\int_{0}^{\widetilde{Q}} P(x) d x-\widetilde{Q} P(\widetilde{Q})=\int_{0}^{\widetilde{Q}} P(x) d x-C(\widetilde{Q})
$$

The net gain in welfare,

$$
\begin{aligned}
\Delta \equiv W(\widetilde{Q}) & =T W_{2}-T W_{1} \\
& =\int_{Q^{d}}^{\widetilde{Q}} P(x) d x-C(\widetilde{Q})+C\left(Q_{i}^{d}\right)+C\left(Q_{j}^{d}\right)
\end{aligned}
$$

Denote

$$
g(q)=\int_{Q^{d}}^{q} P(x) d x-C(q)+C\left(Q_{i}^{d}\right)+C\left(Q_{j}^{d}\right) .
$$

By the concavity of $C(\cdot)$,

$$
g\left(Q^{d}\right)=C\left(Q_{i}^{d}\right)+C\left(Q_{j}^{d}\right)-C\left(Q_{i}^{d}+Q_{j}^{d}\right)>0 .
$$

Again,

$$
g^{\prime}(q)=P(q)-C^{\prime}(q) .
$$

By Assumption 3, $g^{\prime}(q)>0$ iff, $q<\bar{q}$. By Lemma $4, \widetilde{Q}<\bar{q}$ and thus if $Q^{d}<\widetilde{Q}$ then $\Delta=g(\widetilde{Q})>g\left(Q^{d}\right)>0$, as claimed. We are left to prove that $Q^{d}<\widetilde{Q}$.

Since $\pi_{i}^{d} \geq 0$, we have by Assumption 2,

$$
P\left(Q^{d}\right) \geq A C\left(Q_{i}^{d}\right)>A C\left(Q^{d}\right)
$$


Also, $\widetilde{Q}$ is the maximal number such that $P(\widetilde{Q})=A C(\widetilde{Q})$. Namely, for any $q>\widetilde{Q}, P(q)<A C(q)$. Hence, $Q^{d}<\widetilde{Q}$. As a result, total welfare of the society improves.

Remark The following is a simple alternative mechanism which yields the same equilibrium outcome as the one described in Theorem $1 .^{3}$ Consider the subsidy scheme,

$$
\hat{f}(q)= \begin{cases}\delta & \text { if } q \geq \widetilde{Q} \\ -\delta & \text { if } q<\widetilde{Q}\end{cases}
$$

where $\delta>0$ is determined below. The idea is to induce the subsidized firm to produce the output level $\widetilde{Q}$. If it produces $q$, such that $q<\widetilde{Q}$, it will have to pay the regulator a fine of $\delta$. As before, the regulator offers an exclusive contract to the highest bidder. Let $\pi_{1}^{0}, \ldots, \pi_{N}^{0}$ be the Cournot oligopoly profit levels of the firms in the standard non-subsidy case. To eliminate the equilibrium outcome where no firm is bidding for the contract $\hat{f}$, we require $\delta>\pi_{i}^{0}-[\widetilde{Q} P(\widetilde{Q})-C(\widetilde{Q})]$. Otherwise, no firm has an incentive to win the contract even for a zero bid. In addition, $\delta$ should be sufficiently large to guarantee $\delta>\pi_{M}$ where $\pi_{M}$ is the monopoly profit. Otherwise, the subsidized firm is best off deviating from $\widetilde{Q}$ to the monopoly output. It is easy to verify that in every subgame perfect equilibrium at least two firms will bid $\delta$ and the other firms will either bid below $\delta$ or will not bid at all. The winning produces $\widetilde{Q}$ and all the other firms exit the market.

The problem with this mechanism is that the equilibrium outcome is based on weakly dominated strategies. The subsidized firm obtains in equilibrium a zero net payoff but if some firms do not exit the market and produces positive output levels, then the subsidized firm is guaranteed to make a loss. If it does adjust its output level and produce below $\widetilde{Q}$ it will have to pay the fine $\delta$ (in addition to the bid $\delta$ ). If it continues to produce $\widetilde{Q}$, its gross profit is $(\widetilde{Q}+q) P(\widetilde{Q}+q)-C(\widetilde{Q}+q)$ which by definition of $\widetilde{Q}$ (and Assumption 3) is negative.

With the subsidy scheme $f(q, Q)$ given by (4), the regulator takes the risk

\footnotetext{
${ }^{3}$ This mechanism was suggested to us by Elchanan Ben-Porath during a seminar given by one of the authors, held in the Center for Rationality in the Hebrew University of Jerusalem.
} 
of over production. The subsidized firm will end up with zero profit on or off the equilibrium path, since its net profit does not depend on the output levels of the other firms.

\subsection{An Example}

Let $P(q)=a-r q$ and $C(q)=-q^{2}+2 b q$ where $b>0,0 \leq q \leq b, 2 b<a<(r+1) b$ and $r>2$. Then $P(q)=C^{\prime}(q)$ implies $\bar{q}=\frac{a-2 b}{r-2}$ and $P(q)=A C(q)$ implies $\widetilde{Q}=\frac{a-2 b}{r-1}$. Note that $\widetilde{Q}<b$ since $a<(r+1) b$. The total welfare when the regulator offers the subsidy is,

$$
T W_{1}=C S(\widetilde{Q})=\frac{r}{2} \widetilde{Q}^{2}=\frac{r}{2}\left(\frac{a-2 b}{r-1}\right)^{2}
$$

Consider now the case where the regulator offers no subsidy. There are $N$ firms competing a lá Cournot. The profit of every firm is then,

$$
\pi_{i}=q_{i}\left(a-r \sum_{j=1}^{N} q_{j}\right)+q_{i}^{2}-2 b q_{i}, \quad \forall i=1, \ldots, N .
$$

Setting $\frac{\partial \pi_{i}}{\partial q_{i}}=0$, we find that the Cournot output of every firm is

$$
q_{i}^{*}=\frac{a-2 b}{r(N+1)-2}
$$

and the total output is,

$$
Q^{*}=\frac{N(a-2 b)}{r(N+1)-2}<\frac{a-2 b}{r-1}<\widetilde{Q} .
$$

The total industry profit is,

$$
\Pi^{*}=\frac{(r-1) N(a-2 b)^{2}}{[r(N+1)-2]^{2}}
$$

and the consumer surplus is,

$$
C S^{*}=\frac{r}{2} Q^{*}=\frac{r N^{2}}{2}\left[\frac{a-2 b}{r(N+1)-2} \cdot\right]^{2}
$$

Hence the total welfare of the society is,

$$
T W_{2}=\Pi^{*}+C S^{*}=\frac{\left[\frac{r N^{2}}{2}+N(r-1)\right](a-2 b)^{2}}{[r(N+1)-2]^{2}} .
$$


Also,

$$
\frac{\partial T W_{2}}{\partial N}=\frac{r(r-2)(a-2 b)^{2}}{[r(N+1)-2]^{2}}>0 .
$$

Consequently, the total welfare is maximized in a competitive industry (i.e. when $n \rightarrow \infty)$. Now,

$$
\lim _{n \rightarrow \infty} T W_{2}=\frac{1}{2 r}(a-2 b)^{2} \quad \text { and } \quad \lim _{n \rightarrow \infty} T W_{2}<T W_{1}
$$

iff $r^{2}>(r-1)^{2}$, which always holds.

\section{The Case of Non Symmetric Firms}

Consider the case where the $N$ firms are not necessarily symmetric. Their cost functions are $C_{i}\left(q_{i}\right)$, where $i=1, \ldots, N$. Assumptions 2 and 3 are modified accordingly. Namely,

Assumption 2a For every $i, C_{i}\left(q_{i}\right)$ is differentiable for all $q_{i}>0, C_{i}^{\prime}\left(q_{i}\right)>0$ and $C_{i}^{\prime \prime}\left(q_{i}\right)<0$ for all $q_{i}>0 . C(0)=0$ but $\lim _{q_{i} \rightarrow 0} C\left(q_{i}\right) \geq 0$.

Assumption 3a For every i, $P(q)-C_{i}^{\prime}(q)$ is strictly decreasing for all $q>0$ and there exists $\bar{q}_{i}>0$, such that $P\left(\bar{q}_{i}\right)=C_{i}^{\prime}\left(\bar{q}_{i}\right)$.

Lemma 2a For every $i, 1 \leq i \leq N$, there exists $q_{i}$ such that $P\left(q_{i}\right)=A C_{i}\left(q_{i}\right)$.

The proof of Lemma 2a is the same as proof of Lemma 2. Define,

$$
A_{i}=\left\{q_{i} \mid P\left(q_{i}\right)=A C_{i}\left(q_{i}\right)\right\}
$$

and let, $A=\bigcup_{i=1}^{N} A_{i}$.

Lemma 3a The set $A$ is non-empty and compact.

The proof follows from Lemma 3 and from the fact that a finite union of compact sets is compact. 
Let,

$$
\widetilde{Q}=\operatorname{Max}_{q \in A} q
$$

Let $I$ be the set of all firms $i$ such that $\widetilde{Q} \in A_{i}$. Namely, $I$ is the set of all firms such that $P(\widetilde{Q})=A C_{i}(\widetilde{Q})$.

For every $i, 1 \leq i \leq N$, define

$$
f_{i}\left(q_{i}, Q\right)=-q_{i} P(Q)+\int_{0}^{q_{i}} P(x) d x-\left[P(\widetilde{Q})-C_{i}^{\prime}(\widetilde{Q})\right] q_{i}
$$

where $Q$ is the total industry output. Suppose that a firm $i$ is subsidized according to $f_{i}\left(q_{i}, Q\right)$. Then by $(8)$ its net profit is,

$$
\pi_{i}^{S}\left(q_{i}\right)=-C_{i}\left(q_{i}\right)+\int_{0}^{q_{i}} P(x) d x-q_{i}\left[P(\widetilde{Q})-C_{i}^{\prime}(\widetilde{Q})\right]
$$

where $\alpha_{i}$ is the fee it pays to the regulator. Note that $\pi_{i}^{S}$ depends only on $q_{i}$ and not on $Q$. The first order condition of this subsidized firm then is,

$$
\frac{\partial \pi_{i}^{S}}{\partial q_{i}}=P\left(q_{i}\right)-C^{\prime}\left(q_{i}\right)-\left[P(\widetilde{Q})-C^{\prime}(\widetilde{Q})\right]=0
$$

By Assumption 3a, the unique solution is $q_{i}=\widetilde{Q}$. Namely, irrespective of the cost function of the subsidized firm, it will produce $\widetilde{Q}$ units as output.

Next consider the following sequential interaction between the regulator and the firms.

Stage 1. The regulator orders the $N$ firms in a sequence where firms in $I$ have to precede any other firm not in $I$. This sequence is publicly announced.

Stage 2. The regulator makes a "take-it-or-leave-it" offer to the first firm in the sequence (a firm in $I$ ) to subsidize it according to $f_{i}\left(q_{i}, Q\right)$ (given by (8)) in return for an upfront fee $\alpha_{i}=f_{i}(\widetilde{Q}, \widetilde{Q})$. If $i$ accepts the offer, it will become the unique subsidized firm. Otherwise the regulator makes a similar offer to the second firm in the sequence, and so on. If the first $N-1$ firms reject the offer then the regulator will offer the last firm, say $j$, the subsidy schedule $f_{j}\left(q_{j}, Q\right)$ but for a reduced fee of $\alpha_{j}=f_{j}(\widetilde{Q}, \widetilde{Q})-\pi_{j}^{0}$ where $\pi_{j}^{0}$ is the Cournot oligopoly profit of $j$ in case no firm is subsidized and provided that $j$ is not in $I$. If every firm is in $I$, then $\alpha_{j}=f_{j}(\widetilde{Q}, \widetilde{Q})$ 
Stage 3. The firms compete a lá Cournot.

The payoff function of the subsidized firm (if there is one) is given by (9). The payoff function of any other firm $j$ is given by,

$$
\pi_{k}\left(q_{k}\right)=q_{k} P(Q)-C_{k}\left(q_{k}\right)
$$

and the regulator's payoff is the total welfare of the society.

The above mechanism describes a game $G_{a}$.

Theorem 1a Every subgame perfect equilibrium of $G_{a}$ satisfies the following.

i. One firm is subsidized and it is a firm $i$ in $I$ (i.e. $P(\widetilde{Q})=A C_{i}(\widetilde{Q})$ ).

ii. The subsidized firm produces $\widetilde{Q}$ and earns a net profit of zero.

iii. All other firms exit the market.

$i v$. The regulator breaks even.

v. The total welfare of the society is improved.

Proof: As mentioned above, every subsidized firm will produce the output $\widetilde{Q}$. In this case the best reply for any other firm is to exit the market (see proof of Theorem 1). Also similar to the symmetric case, the total welfare under $\widetilde{Q}$ is higher than that of the Cournot oligopoly when no firm is subsidized.

Suppose next that the regulator's offer is rejected by the first $N-1$ firms. Then we argue that the last firm, say $j$, will accept the offer in equilibrium. More precisely, this firm is indifferent between accepting and rejecting the offer $f_{j}\left(q_{j}, Q\right)$ in exchange for $\alpha_{j}=f_{j}(\widetilde{Q}, \widetilde{Q})$, since the net payoff will be $\pi_{j}^{0}$ in both cases. But if $j$ rejects the offer, the regulator has an incentive to slightly reduce his fee $\alpha_{j}$ in order to induce $j$ to accept the offer. The regulator himself benefits from reducing the fee as the total welfare under $\widetilde{Q}$ is strictly larger than that of the Cournot oligopoly when no firm was subsidized. Thus the firm before $j$ in the sequence knows that if it does not accept the offer it would ultimately be driven out by $j$ and hence accepts. Working backwards, it is evident that the 
first firm who has been made the offer by the regulator accepts it readily. The regulator himself breaks even.

\section{Remarks}

1. The regulator is indifferent between the firms who are in $I$ since any of them can costlessly induce the efficient outcome. Therefore, if $|I| \geq 2$, there are multiple equilibria where the subsidized firm could be any one of the firms in $I$, and not necessarily the first in the sequence.

2. In the case where $|I| \geq 2$, Theorem 1a can be obtained in a much simpler mechanism (similar to the one described in the game $\mathrm{G}$ in Section 2). The regulator offers an exclusive subsidy schedule to the highest bidder. The schedule is $f_{i}\left(q_{i}, Q\right)$ given by (8) for some $i \in I$. The competition between the firms in $I$ induce them to bid $\alpha_{i}=f_{i}(\widetilde{Q}, \widetilde{Q}), k \in I$. A firm $j$ not in $I$, however will not be able to afford a bid of $f_{i}(\widetilde{Q}, \widetilde{Q})$ since by definition of $\widetilde{Q}, P(\widetilde{Q})-A C_{j}(\widetilde{Q})<0$. Hence, the subsidized firm is one from $I$. Consequently, the sequential mechanism described in $G_{a}$ is need only if $|I|=1$. 


\section{Appendix}

\section{A Proof of Lemma 3}

First note that there exists $\delta>0$ such that for $0 \leq q<\delta, A C(q)$ and $P(q)$ do not intersect. Indeed, if $C(0)=0$ then $\lim _{q \rightarrow 0} A C(q)=C^{\prime}(0)$ and by Assumption 3 , $\lim _{q \rightarrow 0} A C(q)<P(0)$. By the continuity of $A C(q)$ and $P(q)$, there exists $\delta>0$ such that $A C(q)<P(q)$ for the $q<\delta$. Consequently, $A \subseteq\{q \mid q \geq \delta\}$. By Lemma 2, $A \neq \phi$. Again by Assumption 3, for $q>\bar{q}, P(q)<C^{\prime}(q)<A C(q)$. Hence, $A \subseteq\{q \mid \delta \leq q \leq \bar{q}\}$, and thus is bounded. By the continuity of $A C(\cdot)$ and $P(\cdot)$ for $q>0 \mathrm{~A}$ is closed, implying $A$ is nonempty and bounded.

\section{B Proof of Lemma 5}

We have,

$$
\begin{aligned}
f(\widetilde{Q}) & =-\widetilde{Q} P(\widetilde{Q})+\int_{0}^{\widetilde{Q}} P(x) d x-\widetilde{t} \cdot \widetilde{Q} \\
& =\int_{0}^{\widetilde{Q}} P(x) d x-\widetilde{t} \cdot \widetilde{Q}-C(\widetilde{Q})
\end{aligned}
$$

as $P(\widetilde{Q})=A C(\widetilde{Q})$. Let us show that

$$
\int_{0}^{\widetilde{Q}} P(x) d x-\widetilde{t} \widetilde{Q}>C(\widetilde{Q}) .
$$

Define $S(q)=\int_{0}^{q} P(x) d x-\widetilde{t} q$. Then

$$
S^{\prime}(q)=P(q)-\left[A C(\widetilde{Q})-C^{\prime}(\widetilde{Q})\right] .
$$

Thus $S^{\prime}(q) \geq C^{\prime}(q)$ iff $P(q)-C^{\prime}(q) \geq A C(\widetilde{Q})-C^{\prime}(\widetilde{Q})=P(\widetilde{Q})-C^{\prime}(\widetilde{Q})$.

But the last inequality holds by Assumption 3 for any $0<q \leq \widetilde{Q}$ (since $\widetilde{Q}<\bar{q})$. Also $S^{\prime}(0)=P(0)-\widetilde{t}>P(\widetilde{Q})-\widetilde{t}=C^{\prime}(\widetilde{Q})>0$ and $S(0)=0=C(0)$. Consequently $S(q)>C(q)$ for all $0<q \leq \widetilde{Q}$. In particular, $C(\widetilde{Q})<S(\widetilde{Q})=$ $\int_{0}^{\widetilde{Q}} P(x) d x-\widetilde{t}$ and $\pi_{M}(\widetilde{Q})>0$. 


\section{References}

Auriol, E. and J.-J. Laffont (1992). Regulation by Duopoly. Journal of Economics and Management Strategy 1(3), 507-533.

Baron, D. and R. Myerson (1982). Regulating a Monopolist with Unknown Costs. Econometrica 50, 911-930.

Berg, S. and T. Tschirhart (1988). Natural Monopoly Regulation. Cambridge: Cambridge University Press.

Demsetz, H. (1968). Why Regulate Utilities? Journal of Law and Economics 11, 55-66.

Grimm, V., F. Riedel, and E. Wolfstetter (2003). Implementing Efficient Market Structure. Optimal Licensing in Natural Oligopoly when Tax Revenue Matters. Review of Economic Design 7, 443-463.

Guesnerie, R. and J.-J. Laffont (1978). Taxing Price Makers. Journal of Economic Theory 19, 423-455.

Laffont, J.-J. and J. Tirole (1993). A Theory of Incentives in Procurement and Regulation. Cambridge, MA: The MIT Press.

Liao, C.-H. and Y. Tauman (2002). Implementation of the Socially Best Outcome. Memo: http://ms.cc.sunysb.edu/ ytauman/research.html.

Sappington, D. E. and D. S. Sibley (1988). Regulating without Cost Information: The Incremental Surplus Subsidy Scheme. International Economic Review 29(2), 297-306.

Vogelsang, I. and J. Finsinger (1979). A regulatory adjustment process for optimal pricing by multiproduct monopoly firms. The Bell Journal of Economics 10(1), 157-171. 